\title{
The bloody fate of endothelial stem cells
}

\author{
Hajime Kubo and Kari Alitalo ${ }^{1}$ \\ Molecular/Cancer Biology Laboratory, Haartman Institute, Helsinki University Central Hospital and Biomedicum Helsinki, \\ University of Helsinki, 00014 Helsinki, Finland
}

In the embryo, the decision to become an endothelial cell (EC) is a bold choice that commits a cell to the task of generating the blood and lymphatic vascular systems, which form one of the most important and complex organs in the mammalian body. Embryonic blood vessel formation is guided by incompletely understood developmental cues, which give rise to a vascular network with remarkable precision and reproducibility with respect to the network's organization, branching pattern, treelike hierarchy of vessel sizes, and formation of arteries, veins, and lymphatic vessels (Risau 1997; Weinstein 1999). The decision of choosing a hematopoietic cell (HPC) fate is an equally complex undertaking. Yet, the blood circulatory system formed principally by these two differentiation lineages and by the cardiogenic mesenchyme is the first functional organ system formed during embryonic development.

During early mouse embryogenesis, starting at embryonic day 7.5 (E7.5), HPCs are generated in a close association with the developing vascular system. In the blood islands of the yolk sac where the earliest HPCs appear, both HPC and EC lineages arise almost simultaneously from extraembryonic mesoderm, forming structures in which primitive erythrocytes are surrounded by a layer of angioblasts that give rise to differentiated ECs. The close temporal and spatial relationship of hematopoietic and vascular development led to the hypothesis that the two lineages arise from a common precursor, the hemangioblast (Sabin 1920; Murray 1932). This concept is supported by the shared expression of a number of different genes by both lineages. In contrast to commonly used endothelial markers such as CD34 and Tie2 that are also expressed in adult hematopoietic stem cells (HSCs), Flk1/vascular endothelial growth factor (VEGF) receptor-2 (hereafter VEGFR-2) expression is unique in that it is restricted to the mesodermal precursor cells and ECs, and is down-regulated in HPCs (Risau 1997). It is now well established that VEGFR- $2^{+}$cells represent a common precursor for ECs and HPCs (Kennedy et al. 1997; Choi et al. 1998; Nishikawa et al. 1998). However, the pathway downstream of VEGFR-2 signaling has not been established in the hemangioblasts. In this issue of Genes \& Development, Ema and colleagues (2003) demonstrate that the transcription factor Tall/SCL (T-cell

${ }^{1}$ Corresponding author.

E-MAIL Kari.Alitalo@Helsinki.FI; FAX 358-9-191 25510.

Article and publication are at http://www.genesdev.org/cgi/doi/10.1101/ gad.1071203. acute leukemia/stem cell leukemia) regulates the choice of cell fate in early development into EC, HPC, and smooth muscle cell (SMC) lineages. These results provide an important additional piece into the emerging tentative differentiation scheme of embryonic and adult HPCs and ECs (Fig. 1).

\section{Critical events in the establishment of the circulatory system}

Several results indicate that vascular development may be to a large extent genetically determined and that major problems in vascular network formation are lethal in early postimplantation development, whereas the proper vessel integrity and hemodynamic vascular functions are important throughout embryonic and adult life. Deletion of the Vegfr2 gene abruptly ends both HPC and EC differentiation in embryos, whereas VEGF promotes angioblast differentiation (Shalaby et al. 1995; Carmeliet et al. 1996; Ferrara et al. 1996; Eichmann et al. 1997). In contrast, the other VEGF receptor, VEGFR-1, suppresses hemangioblast commitment into ECs (Fong et al. 1995, 1999). In the embryo, the basic fibroblast growth factor FGF-2 is also involved in the induction of angioblasts from the mesoderm (Flamme and Risau 1992; Cox and Poole 2000). Following the commitment to the EC lineage, the angioblasts cluster and reorganize to form capillary-like tubes. They may migrate extensively during the enlargement and remodeling of the plexus, which involves the sprouting, splitting, fusion, and regression (pruning) of branches that shape the organ-specific vascular hierarchy with directional blood flow. In the process of differentiation into arterial or venous structures, the ECs become surrounded to various degrees by pericytes (PCs) and SMCs with the formation of a pericellular basal lamina that gives support to the vessels. In pathological angiogenesis, the maturation and stabilization of the vessels occur improperly, and the vessels remain immature (Hashizume et al. 2002).

Genetic studies in the zebrafish have shown molecular differences between the arterial and venous ECs even before vessel formation. For example, signals mediated by the Notch1 receptor induce expression of the basic helix-loop-helix transcriptional repressor gridlock, which commits angioblasts to the arterial fate (Lawson et al. 2001; Zhong et al. 2001). VEGF acts upstream of Notch but downstream of the sonic hedgehog gene in 


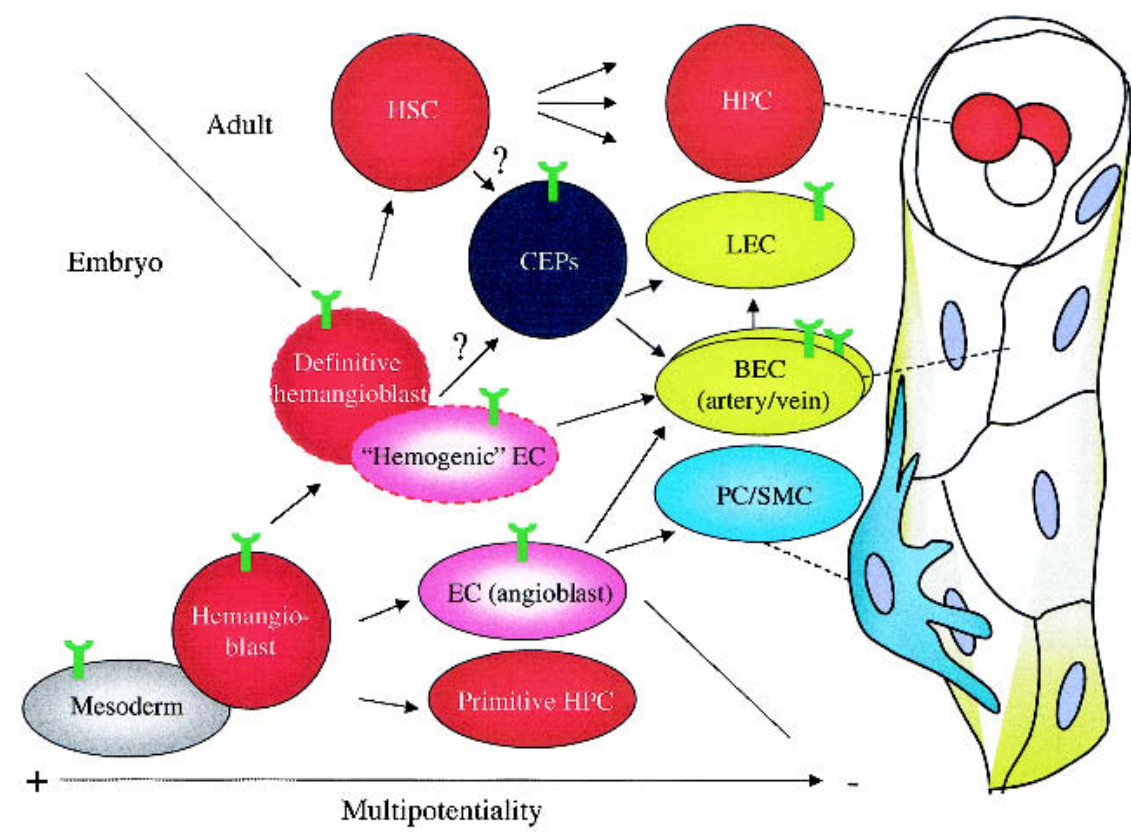

Figure 1. A schematic view of possible developmental lineage relationships of embryonic and adult hematopoietic and endothelial cells. During embryogenesis, the lateral mesoderm or "hemangioblasts" derived from the mesoderm give rise to both primitive hematopoietic (HPC) and endothelial (EC) cell lineages. Part of the pericytes/smooth muscle cells (PC/SMCs) are apparently derived from the ECs. The origin of the definitive (adult-type) HPCs in embryos is not clear, and different views have been presented ranging between the concepts of "definitive hemangioblast" and "hemogenic EC" (delineated by broken lines). After the embryonic differentiation of the arterial and venous endothelial cells (BEC), lymphatic endothelial cells (LECs) are generated from the latter. In adults, the discovery of circulating EC progenitors $(\mathrm{CEP})$, derived from hemangioblastic cells or the hematopoietic stem cells (HSCs), has suggested that adult angiogenesis may operate in part by similar mechanisms as in

the embryos. A blood vessel is shown on the right, with an indication of the corresponding constituent cells. The expression of VEGFR-2 (Y) and Tall (in red, low-level in pink) in the cells has been marked.

arterial differentiation (Lawson et al. 2002). Members of the ephrin family and their corresponding Eph receptors are also important determinants of arterial and venous vessel identity and arterio-venous boundaries during embryonic development (Wang et al. 1998; Adams et al. 1999). The full understanding of the molecular signaling pathways for the commitment to the HPC and EC fates and for EC differentiation is important not only for the understanding of the normal vascular development but also because of the involvement of the reactivation of angiogenic pathways in various diseases.

Following the initial process of primitive hematopoiesis, the site of definitive hematopoiesis shifts to the fetal liver at midgestation, and finally to the bone marrow (BM). Although the origin of the definitive HSCs is still controversial, the aorta-gonad-mesonephros (AGM) region in the mouse and splanchonopleura in the chick are widely accepted as their sites of origin (Muller et al. 1994; Cumano et al. 1996; Medvinsky and Dzierzak 1996). The intraembryonic origin of definitive hematopoiesis is supported by observations of clusters of HPCs that are attached to the ventral wall of the dorsal aorta, as if they were budding from the ECs (Emmel 1915; Oberlin et al. 2002). It was proposed that at least a certain portion of the definitive HPC lineage derives from the ECs in chicks, and in mice, vascular endothelial cadherin-positive cells sorted from the AGM region are capable of reconstituting BM hematopoiesis in irradiated adult mice (Jaffredo et al. 1998; North et al. 2002).

\section{Capturing the elusive hemangioblast-a hemogenic endothelial cell?}

Although the earliest sites of HPC and EC differentiation in the yolk sac blood islands were already identified about 100 years ago, cells with hemangioblast properties have not yet been identified in vivo. However, insight into the molecular events involved in their differentiation has been obtained by gene targeting experiments. Such studies have defined key events in the commitment, growth, and maturation of the HPC and EC lineages. Vegfr-2, which is essential for the development of the hematopoietic and endothelial components of the blood islands, is initially involved in the migration of mesodermal precursor cells to the extraembryonic region of the embryo (Shalaby et al. 1995). The failure of Vegfr2-deficient cells to differentiate may thus reflect the essential role of VEGFR-2 in the migration to a site permissive for hematopoiesis, and, indeed, they are capable of some hematopoiesis in vitro (Hidaka et al. 1999; Schuh et al. 1999). Nevertheless, attempts to identify, isolate, and characterize the precursors representing the elusive hemangioblasts have been notoriously difficult in early embryos. One promising alternative approach to study early HPC and EC development is based on the differentiation potential of embryonic stem (ES) cells in culture.

Recently, analyses of progenitor cells purified from mouse embryos as well as ES cells differentiating in vitro have resolved intermediate stages between the mesodermal cells and committed precursors for the HPC and EC lineages (Ogawa et al. 2001; Mikkola et al. 2003a). Evidence at present suggests that the events leading to the establishment of the HPC and EC lineages from ES cells in culture are similar, if not identical, to those in the embryos. Cultured ES-derived cells with hemangioblastic potential have been identified by the presence of VEGFR-2 ${ }^{+}$progenitors that can give rise to the two lineages (Kabrun et al. 1997; Nishikawa et al. 1998). In the presence of VEGF, these ES-derived precursors can gen- 
erate blast cell colonies in methylcellulose cultures that exhibit HPC and EC potential. The blast colony-forming cells (BL-CFCs) have been shown to express VEGFR-2 and to grow in response to VEGF. They have been proposed to represent the in vitro equivalents of the hemangioblasts.

Whereas the endothelium has been suggested to provide a milieu in which the definitive HPC lineage acquires multiple potentials, several possibilities are available for the cellular origin of definitive hematopoiesis. The finding that vascular endothelial cadherin-positive ECs differentiated from the ES cells serve as the second point of divergence of ECs and definitive HPCs is in agreement with studies on the "hemogenic" potential of ECs lining the embryonic dorsal aorta (Jaffredo et al. 1998; Fujimoto et al. 2001; de Bruijn et al. 2002). These findings demonstrate the important contribution of ES cell differentiation analysis in the identification of distinct intermediate stages of cell differentiation that otherwise would have been difficult to define.

\section{Transcriptional programming of hematopoietic development}

It is known that a variety of growth factors can sustain hematopoiesis. However, individual growth factors are considered not to direct the pathway of differentiation, but rather to be permissive for cell survival and proliferation (Socolovsky et al. 1998). In contrast, transcription factors that are restricted in their expression to particular lineages orchestrate the gene expression programs intrinsic to cell diversification. Thus, despite the important role of VEGFR-2, studies of transcription factors involved in the commitment to ECs and HPCs are of particular interest for the separation of these two lineages. For example, the Tall/SCL and LMO2 (lim domain only) factors are expressed in the yolk sac before differentiation of ECs and HPCs, and a null mutation of either gene causes a complete block in HPC genesis (Robb et al. 1995; Shivdasani et al. 1995; Yamada et al. 1998).

The Tal1 gene, which was originally identified through its translocation in acute T-cell lymphoblastic leukemia, encodes a basic helix-loop-helix transcription factor that is expressed specifically in HPCs, in the vascular endothelium, and in the developing brain (Robb and Begley 1997). Embryos lacking Tall fail to develop past E9.5 because of the absence of yolk sac erythropoiesis, and the corresponding ES cells do not contribute to any HPC lineages in chimeric mice (Robb et al. 1995; Shivdasani et al. 1995; Porcher et al. 1996; Robb et al. 1996). On the other hand, from the presence of ECs in Tal1 $^{-/-}$embryos it was inferred that Tall is dispensable for vascular cell specification despite the fact that it continues to be expressed in the vascular endothelium. Rescue of hematopoietic defects in Tal1-/- embryos using the regulatory elements of the GATA-1 transcription factor and analysis of chimeras generated with $\mathrm{Tal1}^{-/-} \mathrm{ES}$ cells expressing a Tie2-promoter-driven LacZ reporter in the vascular endothelium demonstrated that Tall is es- sential for angiogenic remodeling of the yolk sac capillary network into complex vitelline vessels (Visvader et al. 1998). Despite the genetic evidence that Tall is not required for early endothelial development, the Tall expression pattern in early embryos is similar to that of VEGFR-2 and may mark the hemangioblast (Drake and Fleming 2000). Tall expression is also dependent on VEGFR-2 in mouse embroid bodies (EBs), and VEGFR-2 ${ }^{+}$ $\mathrm{Tall}^{+}$cells are enriched for hemangioblasts, as assessed by the blast colony assay (Chung et al. 2002). Overexpression of Tall in the zebrafish induced an increased number of both HPCs and ECs at the expense of somite and nephrogenic tissues and rescued, though incompletely, the defects of both hematopoiesis and vasculogenesis in the cloche mutant fish, which lack almost all HPCs and ECs (Liao et al. 1998).

The study by Ema et al. (2003) in this issue of Genes \& Development now shows that Vegfr-2-deficient ES cells, in which Tal1 cDNA is inserted into the Vegfr-2 locus, regain blast colony formation in vitro. Ectopic expression of Tall under the Vegfr-2 promoter in Vegfr- $2^{+/-}$ES cells increased the number of BL-CFCs and enhanced their hematopoietic and endothelial potential at the expense of SMC differentiation, whereas loss of Tall promoted SMC formation. These findings suggest a model in which the combinatorial effects of VEGFR-2 and Tall act to regulate cell fate choice in early development into HPC, EC, and SMC lineages. However, whether this model is applicable to the development of definitive intraembryonic HSCs remains to be determined. Nevertheless, using tamoxifen-inducible Tall reactivation in Tal1 ${ }^{-1-}$ EBs, Endoh et al. (2002) recently showed that Tall-dependent specification of both primitive and definitive HPC lineages occurs at the mesodermal stage, prior to the development of the EC lineage.

The AML1 gene (recently renamed Runx1) encodes the DNA-binding subunit of a transcription factor of the core binding factor family. Runx1-deficient embryos develop normal primitive hematopoiesis and early vascular network, but they lack definitive hematopoiesis and die between E11 and E12.5 (Okuda et al. 1996). In addition to the hematopoietic abnormalities, Runx1-deficient embryos also show extensive central nervous system hemorrhage and necrosis, suggesting defects in the vascular development. Although analysis of Runx1 $1^{-/-}$EBs revealed a marked reduction in BL-CFC formation and a complete block in definitive hematopoietic potential, Runxl had no impact on the generation of the primitive erythroid lineages. These findings suggest that these hematopoietic programs diverge at an early stage of development, possibly at the level of the BL-CFC. Thus, two populations of BL-CFCs with distinct primitive and definitive hemangioblastic potential (primitive and definitive hemangioblasts, respectively) would be generated from multipotential BL-CFCs, and only the latter would depend on Runx1 (Lacaud et al. 2002). North et al. (2002) has demonstrated that in Runx1-deficient mice the paraaortic HPC clusters were disrupted, whereas the aortic endothelium was intact, suggesting that Runx1 is involved in the transition of "hemogenic" ECs to defini- 
tive HPCs. However, at this point we do not know the exact relationship of the definitive hemangioblasts and the hemogenic ECs.

\section{Vascular endothelial and smooth muscle development}

The origin of the PC/SMCs surrounding the developing vasculature has been proposed to be largely from neural crest cells and the surrounding mesenchyme. Furthermore, transdifferentiation of SMCs from ECs was recently demonstrated by in vitro and in vivo studies (DeRuiter et al. 1997; Yamashita et al. 2000). Plateletderived growth factor (PDGF)-B was shown to promote SMC differentiation from VEGFR-2 ${ }^{+}$EC cells, and $p d g f b-$ targeted mice showed impaired PC/SMC recruitment (Lindahl et al. 1997). Ema et al. (2003) now find that Tal1 function impinges on SMC differentiation from the ECs. Although Tall is not required for the initial specification and proliferation of the ECs, it is necessary for vascular remodeling of the yolk sac capillary network into branching vitelline vessels. The Tal1 ${ }^{-/}$vascular abnormalities most closely resemble those of embryos lacking the endothelial Tie2 receptor for the angiopoietins (Dumont et al. 1994; Sato et al. 1995). Targeted disruption of several other genes leads to similar phenotypes, perhaps because of aberrant interactions of ECs with the PC/ SMCs. Tall seems to be required in a cell-autonomous fashion for the remodeling of ECs into larger vessels, and the vascular defects associated with loss of Tall appear to be endothelial-specific (Visvader et al. 1998). In such cases, an additional requirement for intact angiogenesis may be the presence of HSCs, as recently demonstrated by Takakura et al. (2000). These authors analyzed Runx1-deficient embryos, which lack definitive hematopoiesis and show defective angiogenesis. In para-aortic splanchnopleural cultures from Runx1-null embryos, the addition of HSCs expressing Ang1 rescued angiogenesis in vitro and promoted EC migration.

\section{Vasculogenic hemangioblasts in adults?}

In the classical models of angiogenesis, ECs are recruited from preexisting neighboring capillaries. However, several recent findings indicate that circulating EC precursors (CEP) may contribute to neovascularization in adult tissues (Asahara et al. 1997; Shi et al. 1998; Hattori et al. 2001). Such CEPs may be derived from either multipotent stem cells or potentially from the HSCs. Recently, Grant et al. (2002) addressed this question directly by establishing HSC-transplant recipients that had durable reconstitution of their HPC lineages with cells expressing the green fluorescent protein. Retinal ischemia was then induced to promote neovascularization, and the newly formed vessels were shown to incorporate BMderived ECs. Previous studies have shown that elevation of plasma VEGF levels by tumors, tissue ischemia, or recombinant adenovirus also promotes the mobilization of endothelial and hematopoietic progenitors (Hattori et al. 2001; Murayama and Asahara 2002). In tumor-resis- tant Id-mutant mice, transplantation of VEGF-mobilized CEPs or BM from wild-type mice restores tumor angiogenesis and tumor growth (Lyden et al. 2001). However, it is as yet poorly understood to what extent the recruitment of VEGF-responsive BM-derived precursors is necessary or sufficient for tumor angiogenesis in general.

In parallel with the discovery of CEPs, several studies have suggested the existence of multipotent adult stem cells that have the potential to replenish several cell lineages in various tissues, even across the germ layer barrier (Orkin 2000). Adult HSCs are defined by their ability to self-renew while functionally repopulating the hematopoietic compartment for the lifetime of an individual. Like other tissue-specific stem cells, HSCs may retain "plasticity" capable of regenerating multiple cell types in nonhematopoietic tissues, including the ECs. Multipotent adult mesenchymal stem cells also differentiate into many specialized cell types in culture and contribute to a wide range of developing tissues when injected into mouse blastocysts. When transplanted into adult mice, they engraft and differentiate into HPCs, epithelial cells and ECs (Jiang et al. 2002). The understanding of the transcriptional regulatory molecules controlling the embryonic differentiation of ECs and HPCs is indispensable for elucidating the molecular basis of this plasticity.

The plasticity or reversibility of the differentiated phenotype is compatible with the idea that differentiation is an ongoing process that necessitates continuous active participation of the key regulators. The transcription factors would simultaneously drive development of one cell lineage and oppose contrary choices, and their continued presence would be required to maintain differentiation. However, this hypothesis has recently been challenged by the conditional deletion of Tal1 in adult BM cells, which retained their capacity for full multilineage hematopoietic reconstitution of recipients in nonselective conditions, circumventing the resulting problems in terminal erythroid and megakaryocytic differentiation (Mikkola et al. 2003b). This result is especially surprising given that Tall expression is enriched in normal HSCs and multipotential progenitors, suggesting a role for Tall in adult HPCs.

\section{VEGF signals in CEP/HSC mobilization and survival in adults}

Although VEGFR-2 has been the focus of angiogenesis studies as a major receptor for VEGF, the role of VEGFR-1 has been more enigmatic. VEGFR-1 is first expressed in the angioblasts, and its targeted inactivation results in increased hemangioblast commitment, leading to hyperproliferation of endothelial-like cells, disorganization of blood vessels, and embryonic lethality at E8.5 (Fong et al. 1995, 1999). VEGFR-1 alone does not mediate mitogenic signals in ECs, and mice lacking the cytoplasmic domain of VEGFR-1 are viable and capable of normal vascular development (Hiratsuka et al. 1998), suggesting that VEGFR-1 behaves as an inhibitory decoy receptor. However, VEGFR-1 may have a signaling role in HPCs and, in particular, in inflammatory cells such as mono- 
cytes and macrophages. In cell culture, monocytes isolated from the tyrosine kinase-deleted VEGFR-1 mice fail to migrate in response to VEGF (Hiratsuka et al. 1998). Recent reports also implicate VEGFR-1 signaling as an important mediator of stem cell recruitment and mobilization, and angiogenesis and inflammation in adults.

Luttun et al. (2002) applied PlGF, which binds only to VEGFR-1, systemically via an osmotic minipump and found enhanced angiogenesis in ischemic myocardium and growth of collateral branches in the ischemic limb. In addition, antibodies against VEGFR-1 suppressed angiogenesis in tumors and in ischemic retina. They also inhibited atherosclerotic plaque formation as well as autoimmune arthritis, including inflammation and joint destruction. The anti-inflammatory effect of VEGFR-1 antibodies apparently occurred as a result of reduced mobilization of BM-derived VEGFR- $1^{+}$HSCs into the peripheral blood, and reduced activation and tissue infiltration of VEGFR-1-expressing leukocytes. On the other hand, HPC recovery after transient suppression of mouse BM by 5-fluorouracil was inhibited by anti-VEGFR-1, but not anti-VEGFR-2 (Hattori et al. 2002). In contrast, adenoviral delivery of PlGF improved recovery because of increased VEGFR-1 $1^{+}$HSCs recruitment, and mobilization via MMP-9 mediated release of c-Kit ligand. In another interesting development of the same theme, Gerber et al. (2002) reported that conditionally VEGF-deleted HSCs did not survive or differentiate in culture and failed to repopulate the hematopoietic compartment of irradiated mice. Inhibition of the VEGF-VEGFR interaction did not induce such phenotypes in wild-type HSCs, whereas ligands specific for VEGFR-1 or VEGFR-2 rescued the survival and differentiation of the mutant cells. The requirement of VEGF for HSCs was thus apparently cell-intrinsic.

\section{Monitoring and engineering of cellular differentiation programs via the ... omes}

Most of the molecules involved in HPC differentiation have been so far discovered as genes involved in chromosomal translocations associated with leukemias, and gene targeting technology has greatly contributed to our understanding of such molecules. However, this paradigm may gradually give way to a more rational approach involving high-throughput cell transfection and gene expression profiling analyses. The various intermediate differentiation lineages that arise from the ES cells can be distinguished by cell-surface or other markers. The recent microarray analyses of enriched HSC populations have started to define genes that characterize "stemness", including transcription factors (Ivanova et al. 2002; Mikkola et al. 2002; Ramalho-Santos et al. 2002). Along with proteomics, this novel technology should provide us with the foundation for a more detailed understanding of the cell lineage relationships and their regulation.

In contrast to HPCs, the further differentiation hierarchy of EC precursors and the tissue-specific heterogene- ity of their terminal differentiation programs have not yet been clarified. For example, the vascular system comprises two distinct arms: the blood vasculature and the lymphatic vessels. In spite of the importance of the lymphatic system, the cell biology of this part of the vascular system has received little attention until recently. Studies over the past five years have revealed the existence of the lymphatic-specific vascular endothelial growth factors VEGF-C and VEGF-D, which serve as ligands for the receptor tyrosine kinase VEGFR-3, and have demonstrated their importance for the normal development of lymphatic vessels (Jeltsch et al. 1997; Makinen et al. 2001a). In the mouse, the development of the lymphatic system starts after the cardiovascular system is already functional. A discrete population of ECs expressing the lymphatic-specific homeobox transcription factor Prox-1 can be identified at E9.5 on one side of the anterior cardinal vein, and at E10.5 the first lymphatic outgrowths can be identified at this location (Wigle et al. 2002).

Thus, lymphatic ECs appear to be derived from venous ECs, although the existence of lymphangioblastic precursor cells cannot yet be dismissed (Salven et al. 2003). Recent studies have demonstrated that the primary lymphatic and blood vascular ECs represent differentiated cell lineages without evidence of any spontaneous interconversion between the distinguishing phenotypic properties (Makinen et al. 2001b). In large-scale genomic expression profiles, lymphatic and blood vascular ECs show differential expression of a number of genes, yet the ectopic overexpression of Prox-1 in blood vascular ECs can induce about one-third of the lymphatic ECspecific gene expression (Petrova et al. 2002). Similar analyses using transfection of transcription factors, corresponding RNAi constructs, and gene expression profiling will certainly be commonly used to describe other aspects of endothelial heterogeneity and the intermediate stages of differentiation of the HPC and EC lineages. The possibilities for modifying the cellular differentiation programs are also great. For example, ectopic expression of a homeotic transcription factor HOXB4 was recently reported to reprogram yolk sac HPCs and ES-derived progenitors into definitive HPCs (Kyba et al. 2002). HOXB4 also induced BM-derived HSC expansion ex vivo, while preserving full lymphoid and myeloid engraftment potential (Antonchuk et al. 2002). In the future we should thus be able to define embryonic and adult hemangioblasts or endothelial stem cells in more accurate terms via their state of genome expression, and to alter their differentiation programs by genetic engineering of the key regulators, thus opening new possibilities for therapeutic applications in regenerative medicine.

\section{Acknowledgments}

We thank Hanna K.A. Mikkola and Stuart H. Orkin for sharing their in press results and Christer Betsholtz, Daniel Dumont, Shin-Ichi Nishikawa, and Toshio Suda for critical comments. We also apologize to those whose papers could not be cited because of space limitations. 


\section{References}

Adams, R.H., Wilkinson, G.A., Weiss, C., Diella, F., Gale, N.W., Deutsch, U., Risau, W., and Klein, R. 1999. Roles of ephrinB2 ligands and EphB receptors in cardiovascular development: Demarcation of arterial/venous domains, vascular morphogenesis, and sprouting angiogenesis. Genes \& Dev. 13: 295306.

Antonchuk, J., Sauvageau, G., and Humphries, R.K. 2002. HOXB4-induced expansion of adult hematopoietic stem cells ex vivo. Cell 109: 39-45.

Asahara, T., Murohara, T., Sullivan, A., Silver, M., van der Zee, R., Li, T., Witzenbichler, B., Schatteman, G., and Isner, J.M. 1997. Isolation of putative progenitor endothelial cells for angiogenesis. Science 275: 964-967.

Carmeliet, P., Ferreira, V., Breier, G., Pollefeyt, S., Kieckens, L., Gertsenstein, M., Fahrig, M., Vandenhoeck, A., Harpal, K., Ebenhardt, C., et al. 1996. Abnormal blood vessel development and lethality in embryos lacking a single VEGF allele. Nature 380: 435-439.

Choi, K., Kennedy, M., Kazaroy, A., Papadimitriou, J.C., and Keller, G. 1998. A common precursor for hematopoietic and endothelial cells. Development 125: 725-732.

Chung, Y.S., Zhang, W.J., Arentson, E., Kingsley, P.D., Palis, J., and Choi, K. 2002. Lineage analysis of the hemangioblast as defined by Flk1 and SCL expression. Development 129: 5511-5520.

Cox, C. and Poole, T.J. 2000. Angioblast differentiation is influenced by the local environment: FGF-2 induces angioblasts and patterns vessel formation in the quail embryo. Dev. Dyn. 218: 371-382.

Cumano, A., Dieterlen-Lievre, F., and Godin, I. 1996. Lymphoid potential, probed before circulation in mouse, is restricted to caudal intraembryonic splanchnopleura. Cell 86: 907-914.

de Bruijn, M.F., Ma, X., Robin, C., Ottersbach, K., Sanchez, M.J., and Dzierzak, E. 2002. Hematopoietic stem cells localize to the endothelial cell layer in the midgestation mouse aorta. Immunity 16: 673-683.

DeRuiter, M.C., Poelmann, R.E., VanMunsteren, J.C., Mironov, V., Markwald, R.R., and Gittenberger-de Groot, A.C. 1997. Embryonic endothelial cells transdifferentiate into mesenchymal cells expressing smooth muscle actins in vivo and in vitro. Circ. Res. 80: 444-451.

Drake, C.J. and Fleming, P.A. 2000. Vasculogenesis in the day 6.5 to 9.5 mouse embryo. Blood 95: 1671-1679.

Dumont, D.J., Gradwohl, G., Fong, G.H., Puri, M.C., Gertsenstein, M., Auerbach, A., and Breitman, M.L. 1994. Dominant-negative and targeted null mutation in the endothelial receptor tyrosine kinase, tek, reveal a critical role in vasculogenesis of the embryo. Genes \& Dev. 8: 1897-1909.

Eichmann, A., Corbel, C., Nataf, V., Vaigot, P., Breant, C., and Le Douarin, N.M. 1997. Ligand-dependent development of the endothelial and hematopoietic lineages from embryonic mesodermal cells expressing vascular endothelial growth factor 2. Proc. Natl. Acad. Sci. 94: 5141-5146.

Ema, M., Faloon, P., Zhang, W.J., Hirashima, M., Reid, T., Stanford, W.L., Orkin, S., Choi, K., and Rossant, J. 2003. Combinatorial effects of Flk1 and Tal1 on vascular and hematopoietic development in the mouse. Genes \& Dev. (this issue).

Emmel, V.E. 1915. The cell clusters in the dorsal aorta of mammalian embryos. Am. J. Anatomy 19: 401-421.

Endoh, M., Ogawa, M., Orkin, S., and Nishikawa, S.I. 2002. $\mathrm{SCL} /$ tal-1-dependent process determines a competence to select the definitive hematopoietic lineage prior to endothelial differentiation. EMBO J. 21: 6700-6708.

Ferrara, N., Carver-Moore, K., Chen, H., Dowd, M., Lu, L.,
O'Shea, K.S., Powelll-Braxton, L., Hilan, K.J., and Moore, M.W. 1996. Heterozygous embryonic lethality induced by targeted inactivation of the VEGF gene. Nature 380: 438-442.

Flamme, I. and Risau, W. 1992. Induction of vasculogenesis and hematopoiesis in vitro. Development 116: 435-439.

Fong, G.H., Rossant, J., Gertsenstein, M., and Breitman, M.L. 1995. Role of the Flt-1 receptor tyrosine kinase in regulating the assembly of vascular endothelium. Nature 376: 66-70.

Fong, G.H., Zhang, L., Bryce, D.M., and Peng, J. 1999. Increased hemangioblast commitment, not vascular disorganization, is the primary defect in flt-1 knock-out mice. Development 126: $3015-3025$.

Fujimoto, T., Ogawa, M., Minegishi, N., Yoshida, H., Yokomizo, T., Yamamoto, M., and Nishikawa, S. 2001. Stepwise divergence of primitive and definitive haematopoietic and endothelial cell lineages during embryonic stem cell differentiation. Genes Cells 6: 1113-1127.

Gerber, H.P., Malik, A.K., Solar, G.P., Sherman, D., Liang, X.H., Meng, G., Hong, K., Marsters, J.C., and Ferrara, N. 2002. VEGF regulates haematopoietic stem cell survival by an internal autocrine loop mechanism. Nature 417: 954-958.

Grant, M.B., May, W.S., Caballero, S., Brown, G.A.J., Guthrie, S.M., Mames, R., Byrne, B.J., Vaught, T., Spoerri, P.E., Peck, A.B., et al. 2002. Adult hematopoietic stem cells provide functional hemangioblast activity during retinal neovascularization. Nat. Med. 8: 607-612.

Hashizume, H., Baluk, P., Morikawa, S., Mclean, J.W., Thurston, G., Roberge, S., Jain, R.K., and McDonald, D.M. 2002. Openings between defective endothelial cells explain tumor leakiness. Am. J. Pathol. 156: 1363-1380.

Hattori, K., Dias, S., Heissig, B., Hackett, N.R., Lyden, D., Tateno, M., Hicklin, D.J., Zhu, Z., Witte, L., Crystal, R.G., et al. 2001. Vascular endothelial growth factor and angiopoietin-1 stimulate postnatal hematopoiesis by recruitment of vasculogenic and hematopoietic stem cells. I. Exp. Med. 193: $1005-1014$.

Hattori, K., Heissig, B., Wu, Y., Dias, S., Tejada, R., Ferris, B., Hicklin, D.J., Zhu, Z., Bohlen, P., Witte, L., et al. 2002. Placental growth factor reconstitutes hematopoiesis by recruiting VEGFR $1^{+}$stem cells from bone-marrow microenvironment. Nat. Med. 8: 841-849.

Hidaka, M., Stanford, W.L., and Bernstein, A. 1999. Conditional requirement for the Flk1 receptor in the in vitro generation of early hematopoietic cells. Proc. Natl. Acad. Sci. 96: 73707375.

Hiratsuka, S., Minowa, O., Kuno, J., Noda, T., and Shibuya, M. 1998. Flt-1 lacking the tyrosine kinase domain is sufficient for normal development and angiogenesis in mice. Proc. Natl. Acad. Sci. 95: 9349-9354.

Ivanova, N.B., Dimos, J.T., Schaniel, C., Hackney, J.A., Moore, K., and Lemischka, I.R. 2002. A stem cell molecular signature. Science 298: 601-604.

Jaffredo, T., Gautier, R., Eichmann, A., and Dieterlen-Lievre, F. 1998. Intraaortic hemopoietic cells are derived from endothelial cells during ontogeny. Development 125: 4575-4583.

Jeltsch, M., Kaipainen, A., Joukov, V., Meng, X., Lakso, M., Rauvala, H., Swartz, M., Fukumura, D., Jain, R.K., and Alitalo, K. 1997. Hyperplasia of lymphatic vessels in VEGF-C transgenic mice. Science 276: 1423-1425.

Jiang, Y., Jahagirdar, B.N., Reinhardt, R.L., Schwartz, R.E., Keene, C.D., Ortiz-Gonzalez, X.R., Reyes, M., Lenvik, T., Lund, T., Blackstad, M., et al. 2002. Pluripotency of mesenchymal stem cells derived from adult marrow. Nature 418: 41-49.

Kabrun, N., Buhring, H.J., Choi, K., Ullrich, A., Risau, W., and Keller, G. 1997. Flk-1 expression defines a population of 
early embryonic hematopoietic precursors. Development 124: 2039-2048.

Kennedy, M., Firpo, M., Choi, K., Wall, C., Robertson, S., Kabrun, N., and Keller, G. 1997. A common precursor for primitive erythropoiesis and definitive haematopoiesis. $\mathrm{Na}$ ture 386: 488-493.

Kyba, M., Perlingeiro, R.C.R., and Daley, G.Q. 2002. HoxB4 confers definitive lymphoid-myeloid engraftment potential on embryonic stem cell and yolk sac hematopoietic progenitors. Cell 109: 29-37.

Lacaud, G., Gore, L., Kennedy, M., Kouskoff, V., Kingsley, P., Hogan, C., Carlsson, L., Speck, N., Palis, J., and Keller, G. 2002. Runx1 is essential for hematopoietic commitment at the hemangioblast stage of development in vitro. Blood 100: $458-466$.

Lawson, N.D., Scheer, N., Pham, V.N., Kim, C.H., Chitnis, A.B., Campos-Ortega, J.A., and Weinstein, B.M. 2001. Notch signaling is required for arterial-venous differentiation during embryonic vascular development. Development 128: 36753683.

Lawson, N.D., Vogel, A.N., and Weinstein, M. 2002. sonic hedgehog and vascular endothelial growth factor act upstream of the Notch pathway during arterial endothelial differentiation. Dev. Cell. 3: 127-136.

Liao, E.C., Paw, B.H., Oates, A.C., Pratt, S.J., Postlethwait, J.H., and Zon, L.I. 1998. SCL/Tal-1 transcription factor acts downstream of cloche to specify hematopoietic and vascular progenitors in zebrafish. Genes \& Dev. 12: 621-626.

Lindahl, P., Johansson, B.R., Leveen, P., and Betsholtz, C. 1997. Pericyte loss and microaneurysm formation in PDGF-B-deficient mice. Science 277: 242-245.

Luttun, A., Tjwa, M., Moons, L., Wu, Y., Angelillo-Scherrer, A., Liao, F., Nagy, J.A., Hooper, A., Priller, J., De Klerck, B., et al. 2002. Revascularization of ischemic tissues by PlGF treatment, and inhibition of tumor angiogenesis, arthritis and atherosclerosis by anti-Flt1. Nat. Med. 8: 831-840.

Lyden, D., Hattori, K., Dias, S., Costa, C., Blaikie, P., Butros, L., Chadburn, A., Heissig, B., Marks, W., Witte, L., et al. 2001. Impaired recruitment of bone-marrow-derived endothelial and hematopoietic precursor cells blocks tumor angiogenesis and growth. Nat. Med. 7: 1194-1201.

Makinen, T., Jussila, L., Veikkola, T., Karpanen, T., Kettunen, M.I., Pulkkanen, K.J., Kauppinen, R., Jackson, D.G., Kubo, H., Nishikawa, S., et al. 2001a. Inhibition of lymphangiogenesis with resulting lymphedema in transgenic mice expressing soluble VEGF receptor-3. Nat. Med. 7: 199-205.

Makinen, T., Veikkola, T., Mustjoki, S., Karpanen, T., Catimel, B., Nice, E.C., Wise, L., Mercer, A., Kowalski, H., Kerjaschki, D., et al. 2001b. Isolated lymphatic endothelial cells transduce growth, survival and migratory signals via the VEGFC/D receptor VEGFR-3. EMBO I. 20: 4762-4773.

Medvinsky, A. and Dzierzak, E. 1996. Definitive hematopoiesis is autonomously initiated by the AGM region. Cell 86: 897906.

Mikkola, H.K., Fujiwara, Y., Schlaeger, T.M., Traver, D., and Orkin, S.H. 2003a. Expression of CD41 marks the initiation of definitive hematopoiesis in the mouse embryo. Blood (In press).

Mikkola, H.A., Klintman, J., Yang, H., Hock, H., Schlaeger, T.M., Fujiwara, Y., and Orkin, S.H. 2003b. Hematopoietic stem cells retain long term repopulating activity and multipotency in the absence of stem cell leukemia (SCL/tal-1) gene. Nature (In press).

Mikkola, I., Heavey, B., Horcher, M., and Busslinger, M. 2002. Reversion of B cell commitment upon loss of Pax5 expression. Science 297: 110-113.
Muller, A.M., Medvinsky, A., Strouboulis, J., Grosveld, F., and Dzierzak, E. 1994. Development of hematopoietic stem cell activity in the mouse embryo. Immunity 1: 291-301.

Murayama, T. and Asahara, T. 2002. Bone marrow-derived endothelial progenitor cells for vascular regeneration. Curr. Opin. Mol. Ther. 4: 395-402.

Murray, P.D.F. 1932. The development in vitro of the blood of early chick embryo. Proc. Roy. Soc. London 11: 497-521.

Nishikawa, S., Nishikawa, S., Hirashima, M., Matsuyishi, N., and Kodama, H. 1998. Progressive lineage analysis by cell sorting and culture identities FLK1 ${ }^{+}$VE-cadherin ${ }^{+}$cells at a diverging point of endothelial and hematopoietic lineages. Development 125: 1747-1757.

North, T.E., de Bruijn, M.F., Stacy, T., Talebian, L., Lind, E., Robin, C., Binder, M., Dzierzak, E., and Speck, N.A. 2002. Runxl expression marks long-term repopulating hematopoietic stem cells in the midgestation mouse embryo. Immunity 16: 661-672.

Oberlin, E., Tavian, M., Blazsek, I., and Peault, B. 2002. Bloodforming potential of vascular endothelium in the human embryo. Development 129: 4147-4157.

Ogawa, M., Fraser, S., Fujimoto, T., Endoh, M., Nishikawa, S., and Nishikawa, S. 2001. Origin of hematopoietic progenitors during embryogenesis. Int. Rev. Immunol. 20: 21-44.

Okuda, T., van Deursen, J., Hiebert, S.W., Grosveld, G., and Downing, J.R. 1996. AML1, the target of multiple chromosomal translocations in human leukemia, is essential for normal fetal liver hematopoiesis. Cell 84: 321-330.

Orkin, S.H. 2000. Stem cell alchemy. Nat. Med. 6: 1212-1213.

Petrova, T.V., Makinen, T., Makela, T.P., Saarela, J., Virtanen, I., Ferrell, R.E., Finegold, D.N., Kerjaschki, D., Yla-Herttuala, S., and Alitalo, K. 2002. Lymphatic endothelial reprogramming of vascular endothelial cells by the Prox-1 homeobox transcription factor. EMBO J. 21: 4593-4599.

Porcher, C., Swat, C.W., Rockwell, K., Fujiwara, Y., Alt, F.W., and Orkin, S.H. 1996. The T cell leukemia oncoprotein SCL/ tal-1 is essential for development of all hematopoietic lineages. Cell 86: 47-57.

Ramalho-Santos, M., Yoon, S., Matsuzaki, Y., Mulligan, R., and Melton, D.A. 2002. "Stemness": Transcriptional profiling of embryonic and adult stem cells. Science 298: 597-600.

Risau, W. 1997. Mechanisms of angiogenesis. Nature 386: 671674.

Robb, L. and Begley, C.G. 1997. The SCL/TAL1 gene: Roles in normal and malignant haematopoiesis. Bioessays 19: 607-613.

Robb, L., Lyons, I., Li, Y., Hartley, L., Kontgen, F., Harvey, R.P., and Metcalf, D. 1995. Absence of yolk sac hematopiesis from mice with a targeted disruption of the scl gene. Proc. Natl. Acad. Sci. 92: 7075-7079.

Robb, L., Elwood, N., Elefancy, A.G., Kontgen, F., Li, R., Barmett, D., and Begley, C.G. 1996. The scl gene product is required for the generation of all hematopoietic lineages in the adult mouse. EMBO J. 15: 4123-4129.

Sabin, F.R. 1920. Studies on the origin of blood vessels and of red corpuscles as seen in the living blastoderm of the chick during the second day of incubation: Contribution to embryology. Carnegie Contrib. Embryol. 9: 213-262.

Salven, P., Mustjoki, S., Alitalo, R., Alitalo, K., and Rafii, S. 2003. VEGFR-3 and CD133 identify a population of CD34 ${ }^{+}$ lymphatic/vascular endothelial precursor cells. Blood 101: $168-172$.

Sato, T.N., Tozawa, Y., Deutsch, U., Wolburg-Buchholz, K., Fujisawa, Y., Gendron-Maguire, M., Gridley, T., Wolburg, H., Risau, W., and Qin, Y. 1995. Distinct roles of the receptor tyrosine kinases Tie-1 and Tie-2 in blood vessel formation. Nature 376: 70-74. 
Schuh, A.C., Faloon, P., Hu, Q.L., Bhimani, M., and Choi, K. 1999. In vitro hematopoietic and endothelial potential of flk- $1^{-/-}$embryonic stem cells and embryos. Proc. Natl. Acad. Sci. 96: 2159-2164.

Shalaby, F., Rossant, J., Yamaguchi, T.P., Gertsenstein, M., Wu, X.F., Breitman, M.L., and Schuh, A.C. 1995. Failure of blood island formation and vasculogenesis in Flk-1-deficient mice. Nature 376: 62-66.

Shi, Q., Rafii, S., Wu, M.H., Wijelath, E.S., Tu, C., Ishida, A., Fujita, Y., Kothari, S., Mohle, R., Sauvage, L.R., et al. 1998. Evidence for circulating bone marrow-derived endothelial cells. Blood 92: 362-367.

Shivdasani, R.A., Meyer, E.L., and Orkin, S.H. 1995. Absence of blood formation in mice lacking the T-cell leukaemia oncoprotein tal-1/SCL. Nature 373: 432-434.

Socolovsky, M., Lodish, H., and Daley, G.Q. 1998. Control of hematopoietic differentiation: Lack of specificity in signaling by cytokine receptors. Proc. Natl. Acad. Sci. 95: 65736575.

Takakura, N., Watanabe, T., Suenobu, S., Yamada, Y., Noda, T., Ito, Y., Satake, M., and Suda, T. 2000. A role for hematopoietic stem cells in promoting angiogenesis. Cell 102: 199209.

Visvader, J.E., Fujiwara, Y., and Orkin, S.H. 1998. Unsuspected role for the T-cell leukemia protein SCL/tal-1 in vascular development. Genes \& Dev. 12: 473-479.

Wang, H.U., Chen, Z.F., and Anderson, D.J. 1998. Molecular distinction and angiogenic interaction between embryonic arteries and veins revealed by ephrinB2 and its receptor EphB4. Cell 93: 741-753.

Weinstein, B.M. 1999. What guides early embryonic blood vessel formation? Dev. Dyn. 215: 2-11.

Wigle, J.T., Harvey, N., Detmar, M., Lagutina, I., Grosveld, G., Gunn, M.D., Jackson, D.G., and Oliver, G. 2002. An essential role for Proxl in the induction of the lymphatic endothelial cell phenotype. EMBO J. 21: 1505-1513.

Yamada, Y., Warren, A.J., Dobson, C., Forster, A., Pannell, R., and Rabbitts, T.H. 1998. The T cell leukemia LIM protein Lmo2 is necessary for adult mouse hematopoiesis. Proc. Natl. Acad. Sci. 95: 3890-3895.

Yamashita, J., Itoh, H., Hirashima, M., Ogawa, M., Nishikawa, S., Yurugi, T., Naito, M., Nakao, K., and Nishikawa, S. 2000. Flk1-positive cells derived from embryonic stem cells serve as vascular progenitors. Nature 408: 92-96.

Zhong, T.P., Child, S., Leu, J.P., and Fishman, M.C. 2001. Gridlock signaling pathway fashions the first embryonic artery. Nature 414: 216-220. 


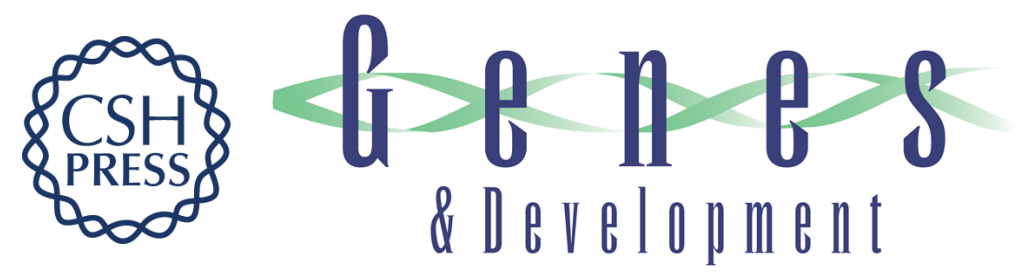

\section{The bloody fate of endothelial stem cells}

Hajime Kubo and Kari Alitalo

Genes Dev. 2003, 17:

Access the most recent version at doi:10.1101/gad.1071203

References This article cites 77 articles, 36 of which can be accessed free at: http://genesdev.cshlp.org/content/17/3/322.full.html\#ref-list-1

License

Email Alerting Receive free email alerts when new articles cite this article - sign up in the box at the top Service right corner of the article or click here.

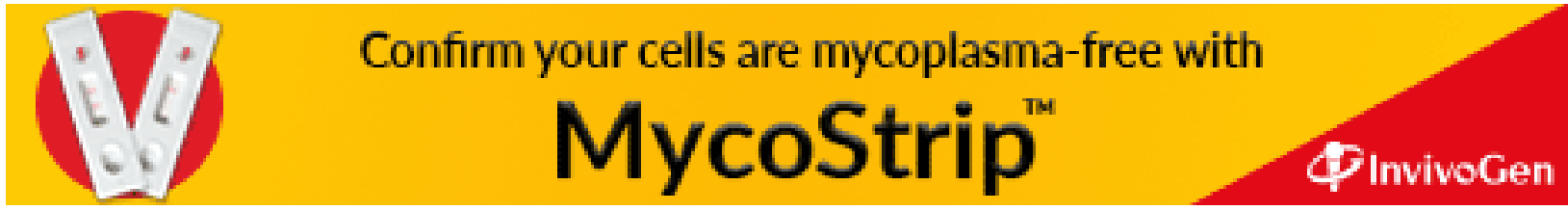

